\title{
Urinary Tract Stenosis
}

National Cancer Institute

\section{Source}

National Cancer Institute. Urinary Tract Stenosis. NCI Thesaurus. Code C79476.

An intrinsic narrowing of a lumen of the urinary tract. 